\title{
cAMP activates calcium signalling via phospholipase $C$ to regulate cellulase production in the filamentous fungus Trichoderma reesei
}

\author{
Yumeng Chen ${ }^{1}$, Xingjia Fan ${ }^{1}$, Xinqing Zhao ${ }^{2}$, Yaling Shen ${ }^{1}$, Xiangyang $\mathrm{Xu}^{3}$, Liujing Wei ${ }^{1}$, Wei Wang ${ }^{\text {* }^{*}}$ \\ and Dongzhi Wei ${ }^{1}$
}

\begin{abstract}
Background: The filamentous fungus Trichoderma reesei is one of the best producers of cellulase and has been widely studied for the production of cellulosic ethanol and bio-based products. We previously reported that $\mathrm{Mn}^{2+}$ and $\mathrm{N}, \mathrm{N}$-dimethylformamide (DMF) can stimulate cellulase overexpression via $\mathrm{Ca}^{2+}$ bursts and calcium signalling in $T$. reesei under cellulase-inducing conditions. To further understand the regulatory networks involved in cellulase overexpression in T. reesei, we characterised the $\mathrm{Mn}^{2+} / \mathrm{DMF}$-induced calcium signalling pathway involved in the stimulation of cellulase overexpression.

Results: We found that $\mathrm{Mn}^{2+} / \mathrm{DMF}$ stimulation significantly increased the intracellular levels of CAMP in an adenylate cyclase (ACY1)-dependent manner. Deletion of acy 1 confirmed that CAMP is crucial for the $\mathrm{Mn}^{2+} / \mathrm{DMF}$-stimulated cellulase overexpression in T. reesei. We further revealed that CAMP elevation induces a cytosolic $\mathrm{Ca}^{2+}$ burst, thereby initiating the $\mathrm{Ca}^{2+}$ signal transduction pathway in T. reesei, and that CAMP signalling causes the $\mathrm{Ca}^{2+}$ signalling pathway to regulate cellulase production in T. reesei. Furthermore, using a phospholipase $C$ encoding gene plc-e deletion strain, we showed that the plc-e gene is vital for cellulase overexpression in response to stimulation by both $\mathrm{Mn}^{2+}$ and DMF, and that CAMP induces a $\mathrm{Ca}^{2+}$ burst through PLC-E.

Conclusions: The findings of this study reveal the presence of a signal transduction pathway in which $\mathrm{Mn}^{2+} / \mathrm{DMF}$ stimulation produces CAMP. Increase in the levels of CAMP activates the calcium signalling pathway via phospholipase $C$ to regulate cellulase overexpression under cellulase-inducing conditions. These findings provide insights into the molecular mechanism of the CAMP-PLC-calcium signalling pathway underlying cellulase expression in T. reesei and highlight the potential applications of signal transduction in the regulation of gene expression in fungi.
\end{abstract}

Keywords: Trichoderma reesei, Cellulase, Adenylate cyclase, Calcium signalling, Cyclic AMP, $\mathrm{Mn}^{2+}$ /DMF stimulation, Filamentous fungi

\footnotetext{
*Correspondence: wadexp@ecust.edu.cn

1 State Key Lab of Bioreactor Engineering, New World Institute

of Biotechnology, East China University of Science and Technology, 130 Meilong Road, P.O.B. 311, Shanghai 200237, China

Full list of author information is available at the end of the article
}

\section{Background}

Lignocellulosic biomass is one of the most abundant, renewable, and relatively inexpensive raw materials for biorefineries. This biomass is used for the production of value-added chemicals and fuels [1-3]. Filamentous fungi are the principal producers of hydrolytic enzymes dedicated to the degradation of lignocellulosic biomass

c) The Author(s) 2021. This article is licensed under a Creative Commons Attribution 4.0 International License, which permits use, sharing, adaptation, distribution and reproduction in any medium or format, as long as you give appropriate credit to the original author(s) and the source, provide a link to the Creative Commons licence, and indicate if changes were made. The images or other third party material in this article are included in the article's Creative Commons licence, unless indicated otherwise in a credit line to the material. If material is not included in the article's Creative Commons licence and your intended use is not permitted by statutory regulation or exceeds the permitted use, you will need to obtain permission directly from the copyright holder. To view a copy of this licence, visit http://creativecommons.org/licenses/by/4.0/. The Creative Commons Public Domain Dedication waiver (http://creativecommons.org/publicdomain/zero/1.0/) applies to the data made available in this article, unless otherwise stated in a credit line to the data. 
[4-6]. The filamentous fungus Trichoderma reesei is one of the best-studied model organisms for the production of hydrolytic enzymes [7-9]. T. reesei harbours a variety of cellulase- and hemicellulase-encoding genes. Their expression is controlled by a complex regulatory network $[8,10]$. A better understanding of the regulatory machinery of $T$. reesei at the molecular level will lead to new metabolic engineering approaches to construct strains capable of more efficient production of cellulase than is presently possible $[5,8]$.

Cellulase production is regulated by a complex signalling cascade and regulatory network [11]. The precise mechanism by which environmental signal-related stimulation regulates the expression of cellulases remains unclear, although key regulators in different signal transduction pathways have been identified recently [12-15]. Recent studies have demonstrated that stimulation of the calcium signal transduction pathway by environmental signals can affect cellulase production and cell metabolism in fungi [12, 16-20]. Chen et al. [12] demonstrated that external $\mathrm{Ca}^{2+}$ stimulated hyphal growth, growthindependent cellulase production, and total protein secretion of T. reesei Rut-C30 involving the $\mathrm{Ca}^{2+} /$ calmodulin-calcineurin-CRZ1 signal transduction pathway. Other authors have reported that high levels of $\mathrm{Ca}^{2+}$ and $\mathrm{Mn}^{2+}$ concentrations generate a prolonged nuclear accumulation of CrzA in Aspergillus nidulans [16, 17]. Martins-Santana et al. [18] demonstrated that $\mathrm{Ca}^{2+}$ acts synergistically with CRZ1 to modulate cellulase gene expression in T. reesei. We previously reported that $\mathrm{Mn}^{2+}$ and the organic solvent $N, N$-dimethylformamide (DMF) can stimulate cellulase overexpression via a calcium signal transduction pathway in T. reesei $[19,20]$. Above all, cellular $\mathrm{Ca}^{2+}$, which is a ubiquitous second messenger, is an important intracellular signalling molecule involved in the regulation of gene expression in fungi stimulated by environmental signals. However, the details of the signal transduction pathway from environmental stimulation to calcium signalling in regulating cellulase gene expression remain unknown in filamentous fungi.

Extensive progress has been made in understanding the importance of the other ubiquitous second messenger, cyclic AMP (cAMP), in filamentous fungi. Exogenous cAMP leads to increased endoglucanase synthesis in $T$. reesei [21]. A positive correlation was observed between intracellular cAMP concentration and cellulase expression levels $[21,22]$. Adenylate cyclase is a crucial component of the cAMP pathway that generates cAMP. $T$. reesei adenylate cyclase (ACY1) has a consistently positive effect on cellulase gene expression [14]. As a secondary messenger, cAMP is also involved in responses to extracellular signals, such as blue light [23] and carbon metabolism [24]. However, the cAMP signal transduction pathway that regulates cellulase gene expression under environmental stimulation in filamentous fungi has not yet been fully elucidated.

In this study, we assessed the signal transduction pathway from $\mathrm{Mn}^{2+} / \mathrm{DMF}$ stimulation to calcium signalling and cellulase production in $T$. reesei under cellulaseinducing conditions. Our results demonstrate that phospholipase $C$ is an important link between cAMP and calcium signalling in cellulase production that occurs in response to $\mathrm{Mn}^{2+} / \mathrm{DMF}$ stimulation. These findings provide evidence for the mechanism of the environmental regulation of cellulase expression in filamentous fungi.

\section{Results \\ $\mathrm{Mn}^{2+} / \mathrm{DMF}$ stimulation produces CAMP in an ACY1-dependent manner}

We previously demonstrated that a biologically relevant level of extracellular $\mathrm{Mn}^{2+}$ or DMF markedly stimulates cellulase overexpression in T. reesei $[19,20]$. As a secondary messenger, cAMP is involved in responses to extracellular signals. To examine whether $\mathrm{Mn}^{2+} / \mathrm{DMF}$ stimulation had any effect on cAMP concentration in T. reesei, precultured mycelia of T. reesei QM6a was inoculated into fresh liquid MM containing 1\% Avicel (cellulase-inducing conditions) as the sole carbon source with no further supplementation, or with the addition of $10 \mathrm{mM} \mathrm{Mn}^{2+}$ or $1 \%$ DMF, as previously described [19].

The intracellular cAMP concentrations of $T$. reesei QM6a after the addition of $\mathrm{Mn}^{2+}$ and DMF are presented in Fig. 1. Stimulation with $10 \mathrm{mM} \mathrm{Mn}^{2+}$ produced a $76.5 \%$ increase in the intracellular cAMP concentration compared with that of the control (no addition) under the same growth conditions. Similarly, stimulation with $1 \%$ DMF resulted in a $74 \%$ increase in intracellular cAMP concentration compared with the control. These results showed that $\mathrm{Mn}^{2+} / \mathrm{DMF}$ stimulation could induce cAMP accumulation in $T$. reesei. Supplementation with forskolin, a direct adenylate cyclase activator [25], also increased the formation of intracellular cAMP by $50 \%$ compared with that of the control (Fig. 1). These results indicate that $\mathrm{Mn}^{2+} / \mathrm{DMF}$ stimulation can result in cAMP accumulation.

To further clarify whether the increased cAMP was mediated by the adenylate cyclase under $\mathrm{Mn}^{2+} / \mathrm{DMF}$ stimulation, we constructed an adenylate cyclase gene acy1 deletion strain $(\triangle a c y 1)$ to detect its function during cAMP accumulation following $\mathrm{Mn}^{2+} / \mathrm{DMF}$ stimulation. The growth rate of the $\Delta a c y 1$ strains was clearly slower than that of the wild-type strain QM6a (Additional File 1: Figure S1), which is consistent with data from Schuster et al. [14]. We then compared the intracellular cAMP concentration in the $\triangle a c y 1$ strain under different conditions. $\mathrm{Mn}^{2+} / \mathrm{DMF}$ or Forskolin supplementation did not 


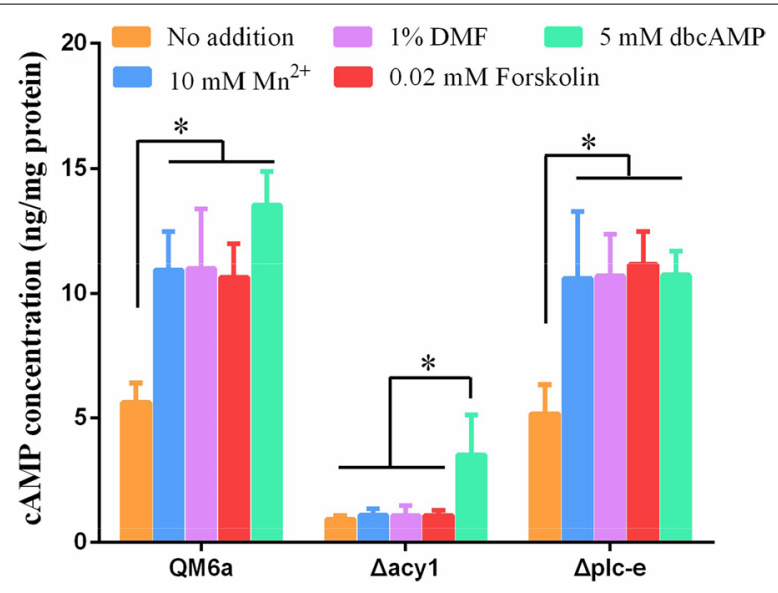

Fig. 1 Intracellular CAMP concentration in T. reesei QM6a, $\triangle a c y$ l and $\Delta p / c$-e strains under different conditions. The QM6a, $\triangle a c y$ 1, and $\Delta p / c-e$ strains were cultured in MM with $2 \%$ glucose as a carbon source and then inoculated into fresh $\mathrm{MM}$ supplemented with $10 \mathrm{mM} \mathrm{Mn}^{2+}$, 1\% DMF, $0.02 \mathrm{mM}$ Forskolin, or $5 \mathrm{mM}$ dbcAMP with 1\% Avicel as the carbon source. Cultures with no added compounds were used as controls. Intracellular CAMP concentration was detected as described in the Materials and Methods. Values are the mean \pm SD of the results from three independent experiments. Asterisks indicate significant differences from the control ${ }^{*} p<0.05$, Student's $t$-test)

induce cAMP accumulation in the $\Delta a c y 1$ strains, which differed from the wild-type strain QM6a (Fig. 1). However, exogenous application of dbcAMP increased the cAMP concentration in both $\triangle a c y 1$ and wild-type QM6a (Fig. 1). The results indicated that $\mathrm{Mn}^{2+} / \mathrm{DMF}$ stimulation can result in cAMP accumulation in an ACY1dependent manner.

\section{CAMP signalling mediates $\mathrm{Mn}^{2+} / \mathrm{DMF}-$ stimulated cellulase overexpression in $T$. reesei}

We found that the concentration of cytosolic cAMP was increased by $\mathrm{Mn}^{2+} / \mathrm{DMF}$ stimulation (Fig. 1). We thus examined whether cAMP signalling was responsible for $\mathrm{Mn}^{2+} / \mathrm{DMF}-$-stimulated cellulase overexpression.

To explore the role of cAMP signalling in $\mathrm{Mn}^{2+}$ / DMF stimulation, cellulase production in the $\Delta a c y 1$ strains in response to $\mathrm{Mn}^{2+}$ and DMF supplementation was detected. As shown in Fig. 2a and b, supplementation with $10 \mathrm{mM} \mathrm{Mn}^{2+}$ or $1 \%$ DMF led to an almost 2.5-fold improvement in cellulase production (CMCase and $p$ NPCase activities) in wild-type QM6a, but did not result in increased cellulase production in the $\Delta a c y 1$ strains. The $p$ NPCase activity in the acyl re-complementation strain Racy1 was similar to that in QM6a (Additional File 2: Figure S2). There was no obvious difference in CMCase or $p$ NPCase activities with and without $\mathrm{Mn}^{2+} / \mathrm{DMF}$ addition in the $\Delta a c y 1$ strains (Fig. 2a, b).
RT-qPCR was performed to determine the transcription levels of the main cellulase genes $c b h 1$ and egl1 in the QM6a and $\triangle a c y 1$ strains in response to $\mathrm{Mn}^{2+} / \mathrm{DMF}$ addition. In agreement with the levels of CMCase and $p$ NPCase activities, deletion of acyl abolished the $\mathrm{Mn}^{2+}$ / DMF-stimulated overexpression of cellulase genes compared with the wild-type strain QM6a at all time points (Fig. 2c, d). Cellulase production was detected in the $\triangle a c y 1$ strains in response to exogenous dbcAMP or dbcAMP in combination with $\mathrm{Mn}^{2+}$ and DMF. As shown in Additional File 3: Figure S3, supplementation with $5 \mathrm{mM}$ dbcAMP led to a significant improvement in cellulase production (CMCase and $p$ NPCase activities) in both $\triangle a c y 1$ strains and wild-type QM6a.

These results indicate that cAMP signalling mediates $\mathrm{Mn}^{2+} / \mathrm{DMF}$-stimulated cellulase overexpression in $T$. reesei.

\section{cAMP elevation can induce cytosolic $\mathrm{Ca}^{2+}$ burst and $\mathrm{Ca}^{2+}$ signalling}

Our previous results suggested that calcium signalling is the key reason for the $\mathrm{Mn}^{2+} / \mathrm{DMF}$-stimulated cellulase overexpression in T. reesei $[19,20]$. Presently, cAMP signalling also appeared to mediate $\mathrm{Mn}^{2+} / \mathrm{DMF}$-stimulated cellulase overexpression (Fig. 2). To gain insight into the relationship between cAMP and calcium signalling, the effect of cAMP on the cytosolic $\mathrm{Ca}^{2+}$ was examined by the use of Fluo-4 AM, a $\mathrm{Ca}^{2+}$-specific fluorescent probe [26].

As illustrated in Fig. 3a and b, the addition of $\mathrm{Mn}^{2+}$, DMF, Forskolin, and dbcAMP induced a $\mathrm{Ca}^{2+}$ burst in wild-type QM6a by increasing cytosolic $\mathrm{Ca}^{2+}$ to concentrations from 70 to $100 \%$ higher than that in cells not cultured with $\mathrm{Mn}^{2+}$, DMF, Forskolin, or dbcAMP. As noted above, $\mathrm{Mn}^{2+}$, DMF, forskolin, and dbcAMP significantly increased the concentration of cytosolic cAMP in QM6a (Fig. 1). These data suggested that a high concentration of cytosolic cAMP is associated with increased cytosolic $\mathrm{Ca}^{2+}$ content (Figs. 1 and 3).

The effect of cAMP on cytosolic $\mathrm{Ca}^{2+}$ was also examined in $\triangle a c y 1$ strains. As shown in Fig. $3 \mathrm{a}$ and b, $\mathrm{Mn}^{2+}$, DMF, and forskolin did not increase the cytosolic $\mathrm{Ca}^{2+}$ concentration in the $\triangle a c y 1$ strains. However, dbcAMP resulted in an approximately $80 \%$ increase in cytosolic $\mathrm{Ca}^{2+}$ concentration in $\Delta a c y 1$ strains compared with the concentration in the absence of any added compound (Fig. 3a, b). Thus, when cAMP synthesis is blocked in $\triangle a c y 1$ strains, $\mathrm{Mn}^{2+}$, DMF, and forskolin addition cannot induce cytosolic $\mathrm{Ca}^{2+}$ burst, while exogenous dbcAMP addition can. This is because dbcAMP can still increase the cytosolic cAMP concentration in $\Delta a c y 1$ strains, while $\mathrm{Mn}^{2+}$, DMF, and Forskolin cannot (Fig. 1). These data suggested that $\mathrm{Mn}^{2+} / \mathrm{DMF}$ stimulation can increase 

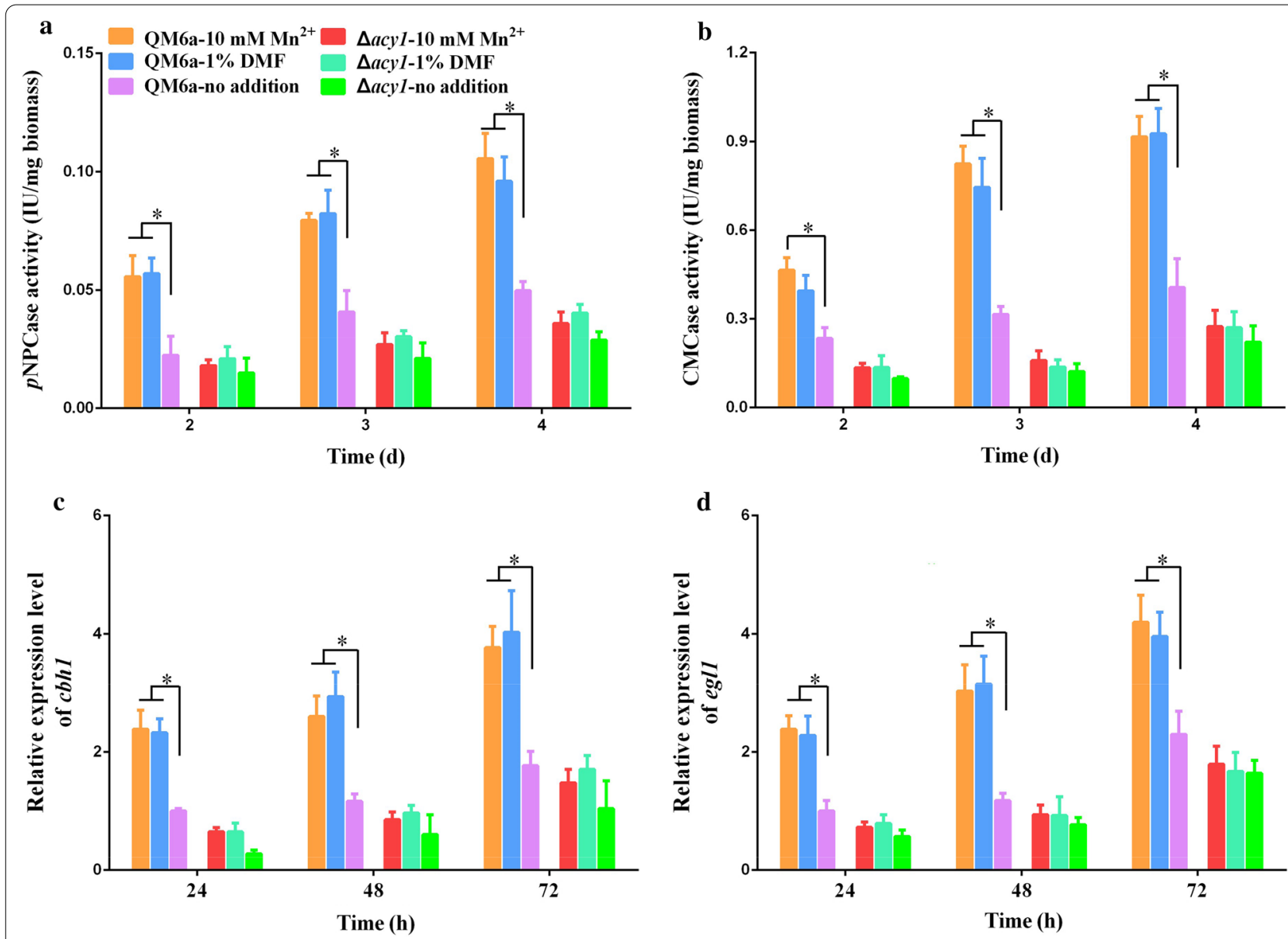

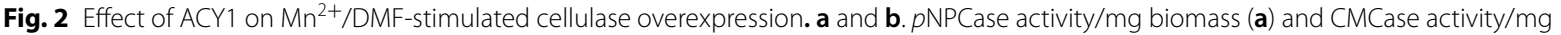
biomass (b) of T. reesei QM6a and $\triangle a c y 1$ strains supplemented with $10 \mathrm{mM} \mathrm{Mn}^{2+}$ or $1 \%$ DMF. $\mathbf{c}$ and $\mathbf{d}$. The relative expression levels of cbh 1 (c) and

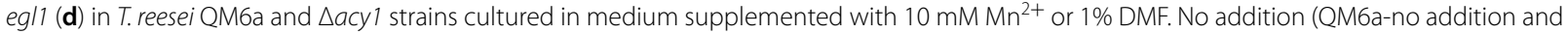
$\triangle a c y$ 1-no addition) were used as controls. The QM6a culture with no addition at $24 \mathrm{~h}$ was used as the reference sample. Values are the mean \pm SD of the results from three independent experiments. Asterisks indicate significant differences from the control $\left({ }^{*} p<0.05\right.$, Student's $t$ test)

cytosolic cAMP content, which induces cytosolic $\mathrm{Ca}^{2+}$ burst in T. reesei QM6a.

The effect of cAMP on $\mathrm{Ca}^{2+}$ signalling was further examined in the QM6a and $\Delta a c y 1$ strains. As shown in Additional File 4: Figure S4, the addition of $\mathrm{Mn}^{2+}$, DMF, and forskolin significantly upregulated the expression levels of three $\mathrm{Ca}^{2+}$ signalling genes (cam, cna, and crz1) in wild-type QM6a compared to untreated cells. However, the expression levels of cam, cha1, and crz1 remained stable in acy1 deletion strains, irrespective of whether $\mathrm{Mn}^{2+}$, DMF, and forskolin were added to the cells. The addition of dbcAMP resulted in an increase in the expression levels of cam, cna1, and crz1 in both wild-type QM6a and $\Delta a c y 1$ strains compared to untreated cells. These data suggest that an increase in cAMP levels induces a cytosolic $\mathrm{Ca}^{2+}$ burst that activates the $\mathrm{Ca}^{2+}$ signal transduction pathway in $T$. reesei.
To further investigate the link between cAMP and $\mathrm{Ca}^{2+}$ signalling, we measured cellulase production in response to exogenous dbcAMP and dbcAMP in combination with $\mathrm{LaCl}_{3} . \mathrm{LaCl}_{3}$ is a plasma membrane $\mathrm{Ca}^{2+}$ channel blocker that inhibits the cytoplasmic $\mathrm{Ca}^{2+}$ burst. As shown in Additional File 5: Figure S5, supplementation with $5 \mathrm{mM}$ dbcAMP led to a significant increase in cellulase production (CMCase and $p$ NPCase activities) in wild-type QM6a. However, cellulase activities decreased significantly when $\mathrm{LaCl}_{3}$ supplements were added compared to the no- $\mathrm{LaCl}_{3}$ control. These results suggest that cAMP signalling causes $\mathrm{Ca}^{2+}$ signalling to regulate cellulase production in T. reesei.

\section{PLC-E mediates both $\mathrm{Mn}^{2+}$ - and DMF-stimulated cellulase overexpression}

To gain further insight into the mechanism by which $\mathrm{Mn}^{2+} / \mathrm{DMF}$ stimulates cellulase overexpression, we 

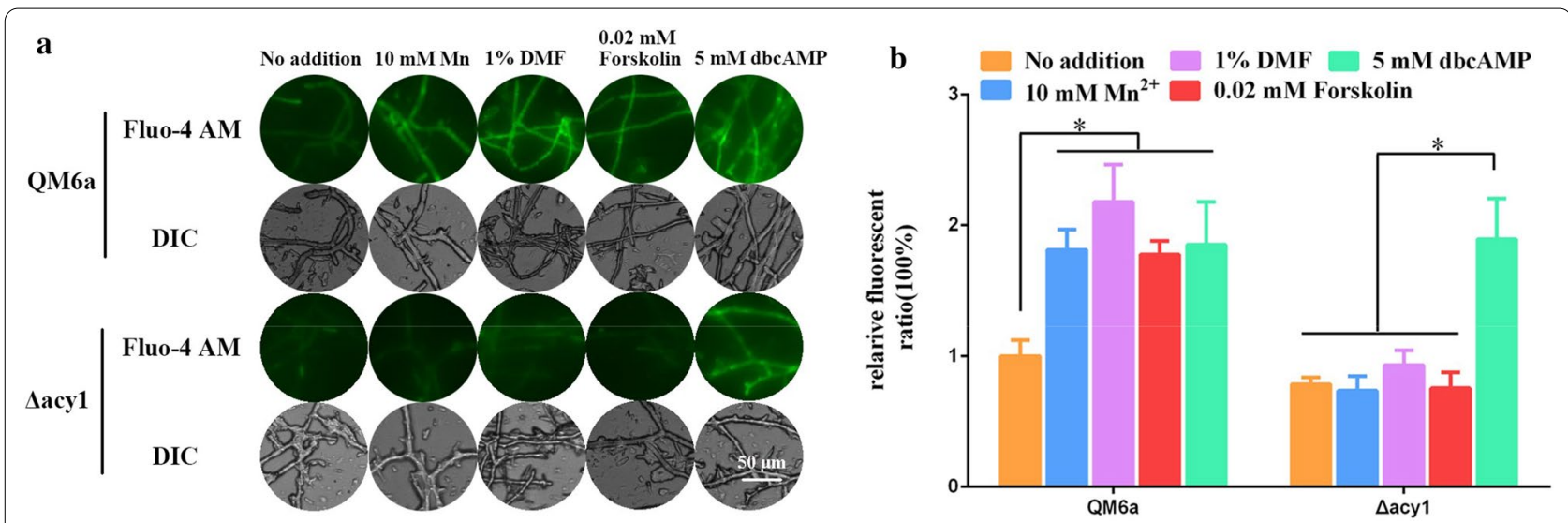

Fig. 3 Cytosolic $\mathrm{Ca}^{2+}$ levels in T. reesei QM6a and $\triangle a c y 1$ strains under different conditions. a The analysis of cytosolic $\mathrm{Ca}^{2+}$ levels using the $\mathrm{Ca}^{2+}$ fluorescent probe Fluo-4 AM. The QM6a and $\triangle a c y 1$ strains were cultured in MM with 2\% glucose as the carbon source, then inoculated to fresh MM supplemented with $10 \mathrm{mM} \mathrm{Mn}{ }^{2+}, 1 \%$ DMF, $0.02 \mathrm{mM}$ Forskolin, or $5 \mathrm{mM}$ dbcAMP with 1\% Avicel as the carbon source. Cultures with no addition was used as the controls. Fluo-4 AM $(50 \mu \mathrm{M})$ was used for detection. The intensity was monitored using automatic inverted fluorescence microscopy. Green fluorescence intensity represents the free cytosolic $\mathrm{Ca}^{2+}$ levels. DIC, differential interference contrast. The control images of QM6a were also used in Fig. 5a. b Comparative fluorescence ratio analysis of different supplementation on cytosolic Ca ${ }^{2+}$ levels in T. reesei QM6a and $\triangle a c y 1$ strains. The $y$-axis represents the $\mathrm{Ca}^{2+}$ fluorescence ratio measured by CLSM, and the $\mathrm{x}$-axis represents the different strains tested. Values are the means \pm SEM of the results from three independent experiments. Asterisks indicate significant differences from the control ${ }^{*} p<0.05$, Student's $t$ test)

compared the transcriptomes of three T. reesei QM6a cultures, with no addition, with the addition of $10 \mathrm{mM}$ $\mathrm{Mn}^{2+}$, or with the addition of $1 \%$ DMF (liquid MM containing $1 \%$ Avicel as the sole carbon source) incubated at $28{ }^{\circ} \mathrm{C}$ and $200 \mathrm{rpm}$ for $36 \mathrm{~h}$ [20]. This resulted in the retrieval of 846 genes that were differentially expressed following $10 \mathrm{mM} \mathrm{Mn}^{2+}$ addition compared to the control (no addition). Of these 846 genes, 580 were up-regulated and 266 were down-regulated (Additional File 6: Figure S6, Additional File 7: Table S1). In our previous study, we compared the transcriptomes of T. reesei QM6a cultured with no additions and the addition of $1 \%$ DMF. We observed that 81 genes were upregulated and 21 were downregulated following 1\% DMF addition, compared to the control [20]. In the current study, we analysed the overlap between the differentially expressed genes regulated by $\mathrm{Mn}^{2+}$ and those in DMF. Sixty-three genes were differentially expressed in the presence of both $\mathrm{Mn}^{2+}$ and DMF (Additional File 8: Table S2). Of these genes, 56 were upregulated and 7 genes were downregulated by both $\mathrm{Mn}^{2+}$ and DMF compared with no addition. The same genes were up- or down-regulated under $\mathrm{Mn}^{2+}$ / DMF stimulation, implying a similar putative mechanism of cellular overexpression by $\mathrm{Mn}^{2+} / \mathrm{DMF}$.

Of the genes that were consistently differentially expressed by both $\mathrm{Mn}^{2+}$ and DMF, 11 cellulose degradation-related genes were significantly upregulated in the presence of $1 \% \mathrm{DMF}$ or $10 \mathrm{mM} \mathrm{Mn}^{2+}$ (Additional File 9: Table S3). Two main cellobiohydrolase-encoding genes (cbh1 and cbh2; IDs: 123,989 and 72,567), three endoglucanase-encoding genes (IDs: 122,081, 120,312, and 49,976), including two main endoglucanase genes (egl1 and egl2), one beta-glucosidase-encoding gene (cel3b; ID: 121,735), a xylanase-encoding gene (xyn3; ID: 120,229), and transcription of accessory proteinencoding genes, including those of swollenin gene swo1 (ID: 123,992) and cip2 (ID: 123,940) [7], were consistently upregulated in response to $10 \mathrm{mM} \mathrm{Mn}{ }^{2+}$ and DMF addition. The transcriptome data agreed with our previous cellulase activity and qPCR results $[19,20]$.

Of the genes that were consistently differentially expressed by both $\mathrm{Mn}^{2+}$ and DMF, the transcriptional levels of plc-e, which encodes a phospholipase $C$ protein, were significantly upregulated in response to $10 \mathrm{mM}$ $\mathrm{Mn}^{2+}$ and DMF addition (Additional File 10: Table S4 and [20]). Phospholipase $C$ activity is related to calcium release from intracellular pools, which increases the concentration of cytosolic $\mathrm{Ca}^{2+}$ resulting in a cytosolic $\mathrm{Ca}^{2+}$ burst [11]. We previously reported that the transcriptional level of plc-e was remarkably upregulated in DMFstimulated strains and suggested that PLC-E is involved in DMF-stimulated cellulase overexpression [20]. The latest results implied that PLC-E might also participate in $\mathrm{Mn}^{2+}$-stimulated cellulase overexpression. Thus, we further examined the role of PLC-E in cellulase overexpression under $\mathrm{Mn}^{2+}$ addition. As shown in Fig. 4, the effect of $\mathrm{Mn}^{2+}$ stimulation on cellulase production was remarkably reduced in the $\Delta p l c-e$ mutant, which was constructed in our previous study [20]. A marked increase in cellulase production (Fig. 4a, b) and the transcription 

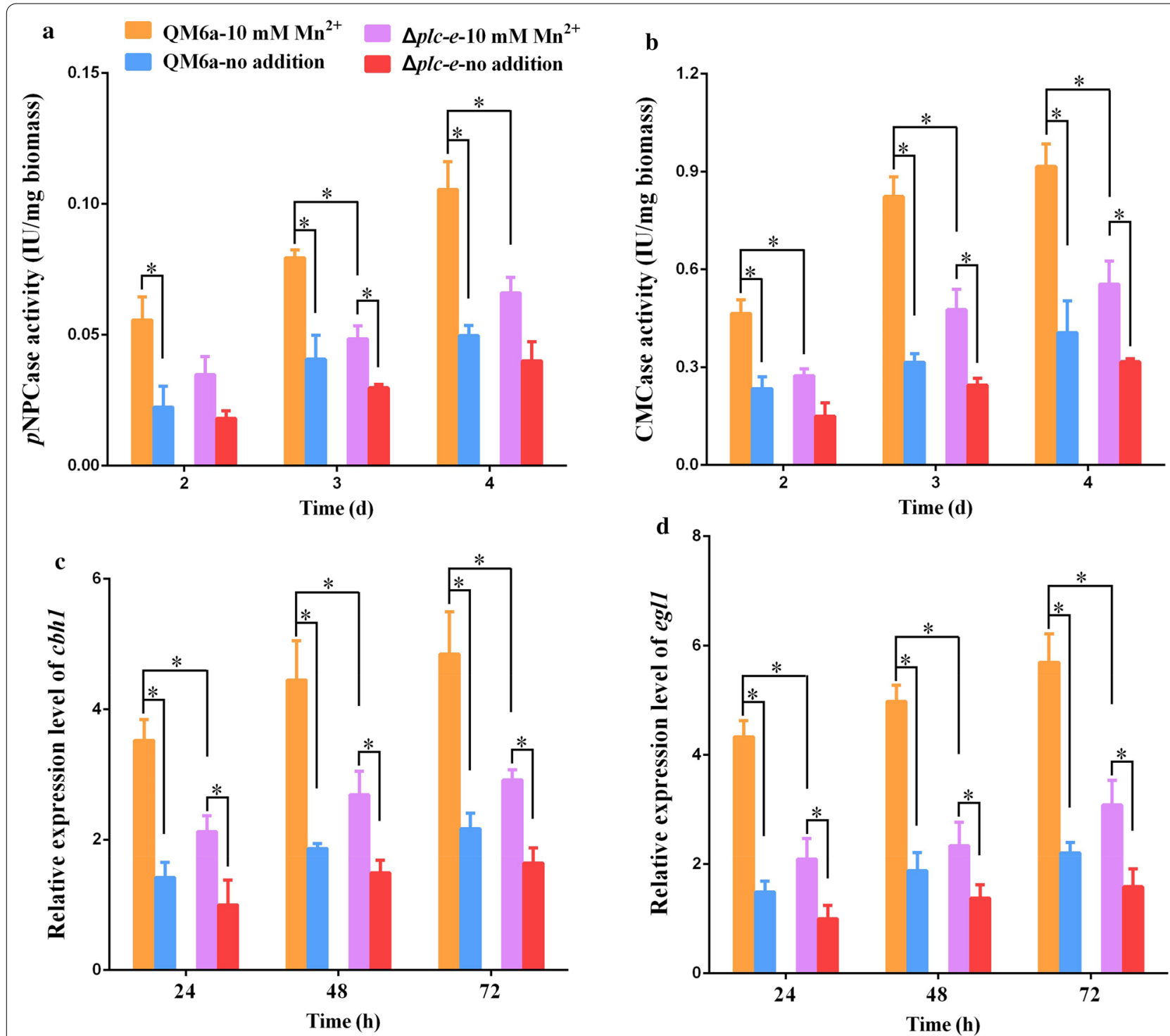

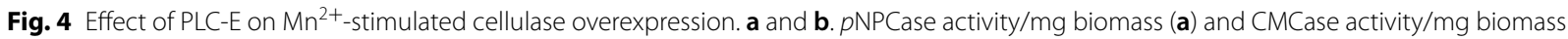
(b) of T. reesei QM6a and $\Delta p / c$-e strains supplemented with $10 \mathrm{mM} \mathrm{Mn}^{2+}$. c and $\mathbf{d}$ The relative expression levels of cbhl (c) and eg/1 (d) in T. reesei

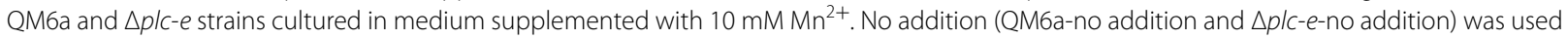
as the respective control. The $\Delta p / c-e$-no addition at $24 \mathrm{~h}$ was used as the reference sample. Values are the mean $\pm S D$ of the results from three independent experiments. Asterisks indicate significant differences from the control ( ${ }^{*} p<0.05$, Student's $t$ test)

levels of the main cellulase genes (Fig. 4c, d) stimulated by $\mathrm{Mn}^{2+}$ were observed in the wild-type QM6a, while the effect of $\mathrm{Mn}^{2+}$ stimulation on cellulase expression was remarkably reduced in the plc-e deletion strain at all time points (Fig. 4). The growth rate related to cellulase activity and transcription levels of $c b h 1$ and egl1 after $\mathrm{Mn}^{2+}$ stimulation in the $\Delta p l c-e$ mutant were significantly decreased compared with those in wild-type QM6a (Additional File 11: Figure S7). The $p$ NPCase activity in the plc-e re-complementation strain Rplc-e was similar to that in QM6a (Additional File 2: Figure S2). These results indicate that PLC-E is vital for cellulase overexpression in response to both $\mathrm{Mn}^{2+}$ and DMF stimulation.

\section{PLC-E exerts an important link between CAMP and $\mathrm{Ca}^{2+}$ signalling in the expression of cellulase}

Earlier studies revealed that extracellular signals can activate phospholipase C (PLC), which is correlated with calcium signalling $[11,27]$. Presently, the $\mathrm{Ca}^{2+}$ burst depended on the accumulation of CAMP, and PLC-E was a mediator in $\mathrm{Mn}^{2+} / \mathrm{DMF}$-stimulated cellulase overexpression (Figs. 3, 4) and [20]. Additionally, the cytosolic 
cAMP concentration in the $\Delta p l c-e$ strains showed no obvious change compared with that of QM6a under $\mathrm{Mn}^{2+} / \mathrm{DMF}$ stimulation, forskolin supplementation, or exogenous dbcAMP addition (Fig. 1). Thus, we hypothesised that PLC-E is an important link between cAMP and $\mathrm{Ca}^{2+}$.

To clarify whether PLC-E is involved in $\mathrm{Ca}^{2+}$ bursts induced by cAMP, the $\mathrm{Ca}^{2+}$ concentration was compared between the QM6a and $\Delta p l c-e$ strains treated with $\mathrm{Mn}^{2+}$, DMF, forskolin, and dbcAMP. The cytosolic $\mathrm{Ca}^{2+}$ levels remained almost stable or were only slightly enhanced in the $\Delta p l c-e$ strains in the presence of $\mathrm{Mn}^{2+} / \mathrm{DMF}$ stimulation, forskolin supplementation, or exogenous dbcAMP addition. A significant $\mathrm{Ca}^{2+}$ burst was observed in wildtype QM6a under all these conditions compared with that of the untreated control (Fig. 5a, b). The cytosolic $\mathrm{Ca}^{2+}$ burst induced by cAMP was significantly weakened in the $\Delta$ plc-e strains. These results suggest that PLC-E mediates the $\mathrm{Ca}^{2+}$ burst induced by cAMP. Additionally, the cytosolic cAMP concentration in the $\Delta p l c-e$ strains was similar to that of QM6a under conditions of $\mathrm{Mn}^{2+} / \mathrm{DMF}$ stimulation, forskolin supplementation, or exogenous dbcAMP addition (Fig. 1). These results suggest that cAMP induces $\mathrm{Ca}^{2+}$ bursts through PLC-E. Furthermore, the significantly upregulated expression levels of three $\mathrm{Ca}^{2+}$ signalling genes (cam, cna and $\mathrm{crz} 1$ ) in wild-type QM6a induced by cAMP were significantly weakened in the $\Delta p l c-e$ strains (Additional File 12: Figure S8). The collective results implicated PLC-E as an important link between cAMP and $\mathrm{Ca}^{2+}$ signalling in cellulase expression.

\section{Discussion}

The cAMP pathway is a central signalling cascade with crucial functions in all organisms [11]. We found that in response to $\mathrm{Mn}^{2+} / \mathrm{DMF}$ stimulation, the intracellular cAMP concentration was significantly increased and that the cAMP elevation was responsible for $\mathrm{Mn}^{2+} / \mathrm{DMF}-$ stimulated cellulase overexpression (Figs. 1 and 2). These results were similar to the reports that the formation of cellulase can be altered by the addition of cAMP in T. reesei $[21,28]$. We further obtained evidence that adenylate cyclase ACY1, the central component of the cAMP pathway, mediates $\mathrm{Mn}^{2+} / \mathrm{DMF}$-stimulated cAMP accumulation and cellulase overexpression (Figs. 1 and 2). These data provide insights into the role of cAMP signalling in response to $\mathrm{Mn}^{2+} / \mathrm{DMF}$ stimulation.

Communication between cells and the environment is crucial for the survival of organisms. Cell surface receptors, such as G-protein-coupled receptors (GPCRs), act as sensors to connect to the environment [11, 29]. GPCRs react to a variety of extracellular cues and influence numerous regulatory pathways via the heterotrimeric G-protein signalling cascade, which plays a central role in signal transduction in filamentous fungi [11]. Some $\mathrm{G}$ proteins can activate adenylyl cyclase, resulting in increased cAMP production [30]. The cAMP signal is a well-known downstream target of $\mathrm{G} \alpha$ subunits in filamentous fungi [31] and can cross-talk with other signalling pathways, including calcium signalling. In Saccharomyces cerevisiae, GPCR Gpr1 interacts with Gpa2 and is required for stimulation of cAMP synthesis [32]. In Cryptococcus neoformans, GPCR Gpr4 interacts with

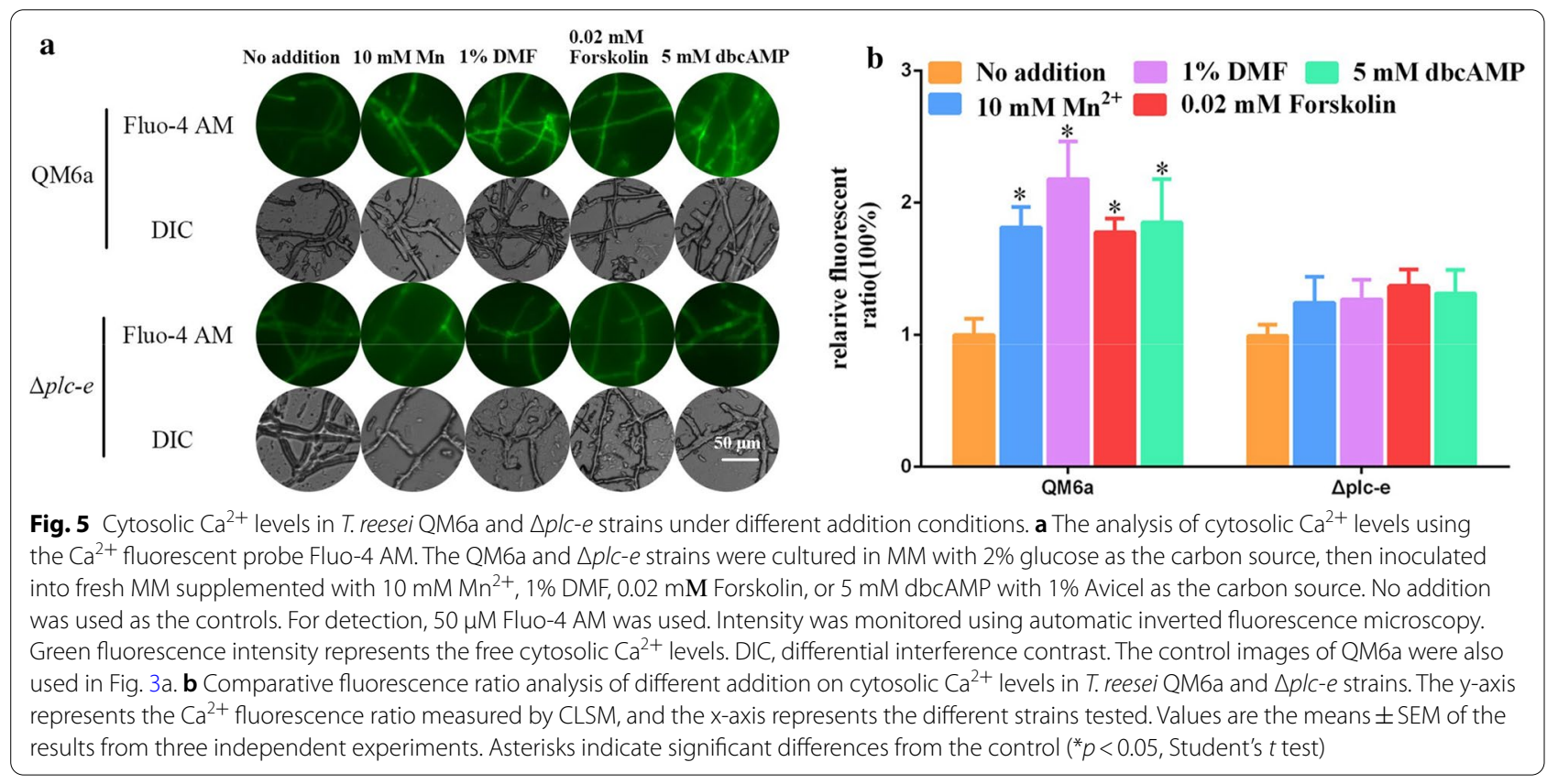


$\mathrm{G} \alpha$ protein $\mathrm{Gpa} 1$ to regulate downstream elements of the cAMP pathway [33]. In T. reesei, Ga protein GNA3 is involved in the control of cAMP concentrations [22]. These data indicate that the cAMP pathway represents the main output of GPCRs and G-protein signalling. A transcriptome study found that seven GPCR-encoding genes were upregulated in the presence of $10 \mathrm{mM} \mathrm{Mn}^{2+}$. The seven genes included one GPCR Tr72004 affiliated with the cAMP receptor-like family, four PTH11-type GPCR-encoding genes $(\operatorname{Tr} 110339, \operatorname{Tr} 124113, \operatorname{Tr} 121990$, Tr62462), and two GprK-type GPCR-encoding genes (Tr37525 and $\operatorname{Tr} 81383)$ (Additional File 11: Table S5). Presently, one GprK-type GPCR-encoding gene ( $\operatorname{Tr} 81383)$ was significantly upregulated in the presence of 1\% DMF (Additional File 13: Table S5). These GPCRs might relate to adenylate cyclase ACY1 activation and intracellular cAMP accumulation in the presence of $\mathrm{Mn}^{2+}$ and DMF (Fig. 1). These data implied the complex transduction of signals in $T$. reese $i$ via the GPCR cascade under $\mathrm{Mn}^{2+} / \mathrm{DMF}$ stimulation.

Calcium and calcium signalling play crucial roles in intracellular signalling processes in lower eukaryotes
$[11,27]$. Calcium signalling is mediated by the cytosolic $\mathrm{Ca}^{2+}$ concentration to activate appropriate downstream responses [27, 34]. The calcium signalling pathway interacts with other signalling pathways, such as cAMP signalling, alkaline $\mathrm{pH}$ signalling, and reactive oxygen species [27, 35-37]. In the present study, cross-talk was evident between cAMP and $\mathrm{Ca}^{2+}$ signals under $\mathrm{Mn}^{2+}$ / $\mathrm{DMF}^{-}$stimulated cellulase overexpression (Fig. 6). Similar results were reported in a previous study, in which an increase in cAMP mobilised $\mathrm{Ca}^{2+}$ from intracellular stores and also activated the influx of $\mathrm{Ca}^{2+}$ from the extracellular medium in Plasmodium falciparum [35]. Another similar study showed that cAMP-mediated phosphorylation regulated calcium homeostasis by activating calcium channels in Aspergillus niger [38]. The collective prior and present results indicate a highly complex relationship between the $\mathrm{Ca}^{2+}$ and cAMP signalling pathways in the regulation of the expression of the corresponding genes under different environmental signals. This study demonstrates that PLC is an important link between cAMP and calcium signalling pathways in cellulase expression. However, other cross-talk between

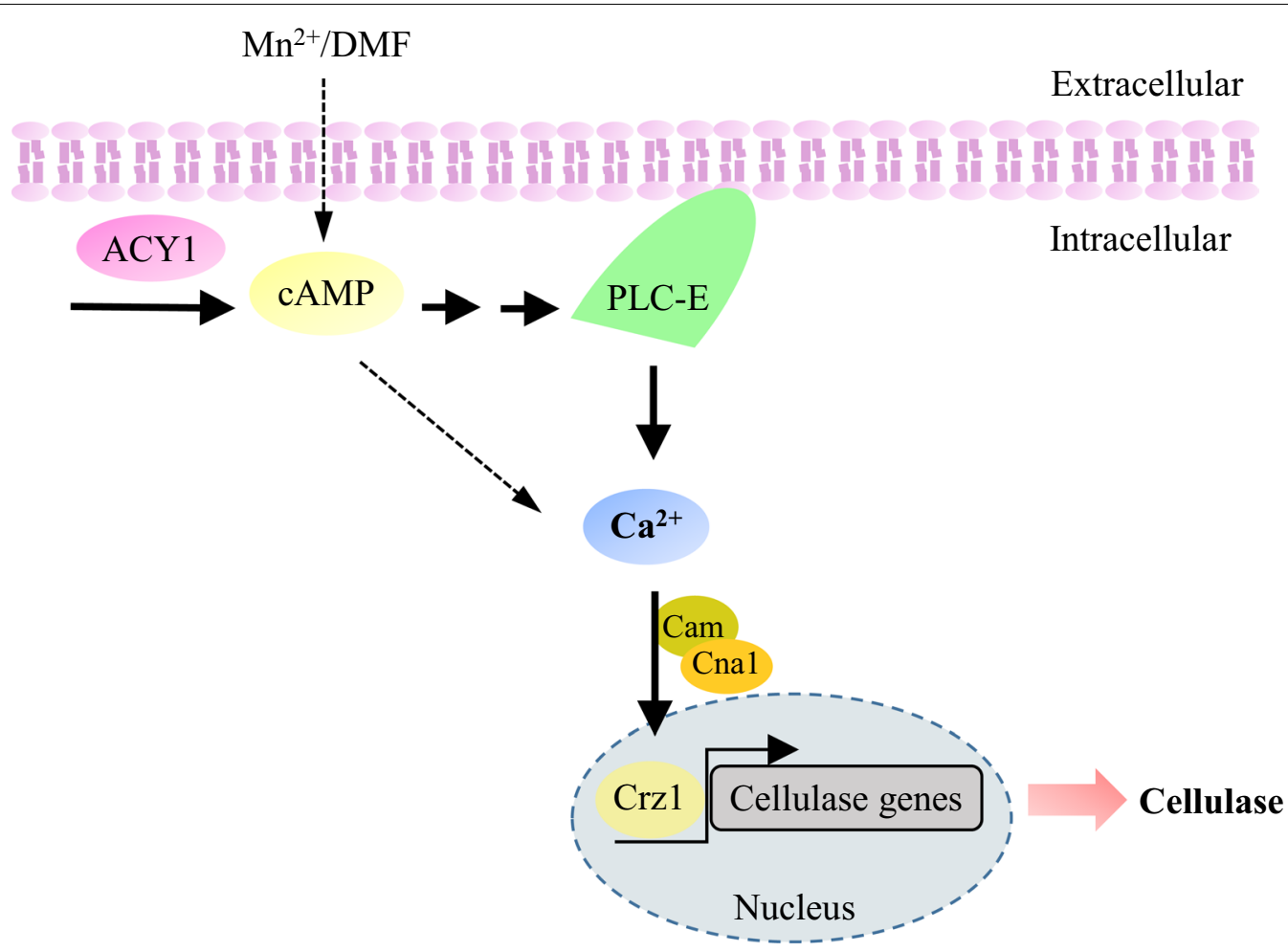

Fig. 6 Mechanistic model of the CAMP and calcium signalling pathway in cellulase overexpression responding to $\mathrm{Mn}^{2+} / \mathrm{DMF}$ stimulation in T. reesei under cellulase-inducing conditions. Mn ${ }^{2+}$ /DMF stimulation induces intracellular CAMP accumulation in an adenylate cyclase (ACY1)-dependent manner. An increase in CAMP levels induces a cytosolic $\mathrm{Ca}^{2+}$ burst that stimulates the $\mathrm{Ca}^{2+}$ signal transduction pathway to regulate cellulase expression in T. reesei under cellulase-inducing conditions. PLC is vital for cellulase overexpression in response to stimulation by both $\mathrm{Mn}^{2+}$ and DMF. CAMP induces $\mathrm{Ca}^{2+}$ bursts via PLC-E. The solid arrows indicate data supported by our own experiments, and the dashed arrows indicate other unknown regulation pathways 
these two pathways remains unclear and requires further investigation.

Early studies revealed that PLC is related to calcium signalling [11, 27]. Extracellular signals can activate PLC and increase inositol-1,4,5-trisphosphate (IP3) levels, leading to the release of $\mathrm{Ca}^{2+}$ from internal stores, resulting in a cytosolic $\mathrm{Ca}^{2+}$ burst $[11,39]$. G proteins and cAMP can activate PLC, which in turn induces $\mathrm{Ca}^{2+}$ release $[40,41]$. In B. cinerea, activation of calcium signalling by increased cytosolic $\mathrm{Ca}^{2+}$ mediated by $\mathrm{G}$ proteins and PLC has been observed [41]. Early studies indicated that cAMP activates Epac1, which in turn activates PLC and ensures calcium signalling activation [40]. Cellular calcium homeostasis is regulated by cAMPmediated protein kinase A-dependent phosphorylation. The present data suggest that PLC-E is responsible for the increase in cytosolic $\mathrm{Ca}^{2+}$ and cellulase overexpression induced by cAMP in response to $\mathrm{Mn}^{2+}$ /DMF stimulation in T. reesei (Fig. 6). The mechanism of cAMP activates PLC-E requires further investigation. Deletion of plc-e reduced the resulting cellulase activity upon the addition of $\mathrm{Mn}^{2+} / \mathrm{DMF}$, not completely blocked the resulting cellulase activity upon the addition of $\mathrm{Mn}^{2+}$ / DMF (Fig. 4), and the cytosolic $\mathrm{Ca}^{2+}$ levels were slightly elevated in the $\Delta p l c-e$ strains when exogenous dbcAMP was added (Fig. 5). These results implied the presence of a second signal transduction pathway from cAMP to $\mathrm{Ca}^{2+}$, except plc-e (Fig. 6). These findings provide insights into the mechanism of the CAMP-PLC-calcium signalling pathway in response to environmental stimulation. The findings also indicate that the regulatory mechanisms of cellulase expression involve a complex signalling network in fungi.

\section{Conclusions}

In summary, cellulase production is regulated by complex signal transduction pathways in response to environmental signal stimulation. We studied the signal transduction pathway, in which $\mathrm{Mn}^{2+} / \mathrm{DMF}$ stimulation increased cAMP levels in an ACY1-dependent manner. cAMP then induces a $\mathrm{Ca}^{2+}$ burst through PLC-E to improve cellulase expression in T. reesei (Fig. 6). These findings shed new light on the molecular mechanism of the CAMP-PLCcalcium signalling pathway underlying cellulase expression in filamentous fungi.

\section{Methods}

\section{Strains and growth conditions}

Escherichia coli DH5 $\alpha$ was used for plasmid amplification. Agrobacterium tumefaciens strain AGL-1 was used for fungal transformation [42]. T. reesei QM6a (ATCC 13631) was used throughout the study. E. coli and $A$. tumefaciens were cultured in Luria broth (LB) medium.
All strains of $T$. reesei were maintained on potato dextrose agar (PDA) plates at $28{ }^{\circ} \mathrm{C}$. Conidia were collected from the PDA plates. All strains were cultured in the dark.

Minimal medium (MM; urea $0.3 \mathrm{~g} / \mathrm{L} ;\left(\mathrm{NH}_{4}\right)_{2} \mathrm{SO}_{4}$ $5 \mathrm{~g} / \mathrm{L} ; \mathrm{KH}_{2} \mathrm{PO}_{4} 15 \mathrm{~g} / \mathrm{L} ; \mathrm{MgSO}_{4} 0.6 \mathrm{~g} / \mathrm{L} ; \mathrm{CaCl}_{2} 0.6 \mathrm{~g} / \mathrm{L}$; $\mathrm{FeSO}_{4} \cdot 7 \mathrm{H}_{2} \mathrm{O} \quad 5 \mathrm{mg} / \mathrm{L} ; \quad \mathrm{ZnSO}_{4} \cdot 7 \mathrm{H}_{2} \mathrm{O} \quad 1.4 \mathrm{mg} / \mathrm{L}$; $\left.\mathrm{CoCl}_{2} \cdot 6 \mathrm{H}_{2} \mathrm{O} 2 \mathrm{mg} / \mathrm{L} ; \mathrm{pH} 5.5\right)$ with $2 \%$ glucose or $1 \%$ Avicel was used to assess hyphal growth and cellulase production. Conidia $\left(2 \times 10^{6}\right)$ were cultivated at $28{ }^{\circ} \mathrm{C}$ (200 rpm) in $50 \mathrm{~mL}$ of MM (2\% glucose as the sole carbon source) for 36-48 h. The mycelia were inoculated into $100 \mathrm{~mL}$ of freshly prepared MM containing $1 \%$ Avicel as the sole carbon source with no further addition or the addition of $\mathrm{Mn}^{2+}$ (final concentration $10 \mathrm{mM}$ ), DMF (final concentration 1\%), forskolin (final concentration $10 \mu \mathrm{M}$; Beyotime, Shanghai, China), or dibutyryl cAMP (dbcAMP, final concentration $5 \mathrm{mM}$; Sigma-Aldrich, St. Louis, MO, USA) as described previously [19]. Mycelia were grown for $96 \mathrm{~h}$ at $28^{\circ} \mathrm{C}$. One millilitre of culture liquid was collected at 24-h intervals to perform the assays.

\section{Enzymatic activity}

Cellulase activity was measured as previously described [19]. In brief, the $p$ NPCase activity was determined against $5 \mathrm{mM} p$-nitrophenol-D-cellobioside ( $p$ NPC, Sigma-Aldrich) as the substrate in $50 \mathrm{mM}$ sodium acetate buffer at $\mathrm{pH} 5.0$ and $50{ }^{\circ} \mathrm{C}$ for $30 \mathrm{~min}$. One unit of $p$ NPCase activity was defined as $1 \mu \mathrm{mol}$ of $p$-nitrophenol released per min. CMCase activity was determined using $1 \%$ carboxymethylcellulose (CMC, Sigma-Aldrich) as the substrate in $50 \mathrm{mM}$ sodium acetate buffer at $\mathrm{pH}$ 5.0 , and $50{ }^{\circ} \mathrm{C}$ for $30 \mathrm{~min}$. One unit of CMCase activity was defined as the amount of enzyme producing $1 \mu \mathrm{mol}$ of reducing sugar per min. Biomass concentration was indirectly measured by calculating the amount of total intracellular proteins, as described by Chen et al. [19]. CMCase and $p$ NPCase activities were used to represent cellulase activity.

\section{RNA isolation and RT-qPCR}

RNA extraction and RT-qPCR were performed as described by Chen et al. [19]. In brief, the FastRNA Pro Red Kit (MPbio, Irvine, CA, USA) was used to extract total RNA from mycelia. The TransScript OneStep gDNA Removal and cDNA Synthesis SuperMix (TransGen Biotech, Beijing, China) were used to synthesise cDNA from total RNA according to the manufacturer's instructions. For RT-qPCR, the PerfectStart ${ }^{\mathrm{TM}}$ Green qPCR SuperMix (TransGen Biotech) was used to analyse the transcriptional levels of the main cellulase genes $c b h 1$ (encoding cellobiohydrolase I) and egl1 (encoding endoglucanase I) using the $2^{-\Delta \Delta C t}$ method. The sequences of 
the primers used in RT-qPCR are described in Additional File 14: Table S6. The transcriptional levels of sar1 were measured for data normalisation [43].

\section{Determination of intracellular cAMP concentration}

Cultures of liquid mycelia were harvested and frozen in liquid nitrogen. Intracellular cAMP extraction and determination were performed as previously described [44] with some modifications. In brief, the harvested mycelia were individually ground to a fine powder in liquid nitrogen and resuspended in phosphate-buffered saline (PBS, $\mathrm{pH}$ 7.0). After centrifugation, the supernatants were used to measure the intracellular concentration using the Microorganism cyclic adenosine monophosphate (cAMP) ELISA Kit (mlbio, Shanghai, China) according to the manufacturer's protocol. The total protein content in each sample was determined using the Enhanced BCA Protein Assay Kit (Beyotime, Shanghai, China). The content of intracellular cAMP was expressed relative to the protein concentration in the same sample.

\section{Free cytosolic $\mathrm{Ca}^{2+}$ labelling and detection}

Fluo-4 AM (Beyotime, Shanghai, China) was used as a $\mathrm{Ca}^{2+}$-specific probe to assess cytoplasmic $\mathrm{Ca}^{2+}$ concentrations according to the manufacturer's protocol [26]. The mycelia were loaded with Fluo-4 AM (final concentration $5 \mu \mathrm{M}$ ) at $28{ }^{\circ} \mathrm{C}$ for $30 \mathrm{~min}$ and were washed three times with PBS ( $\mathrm{pH}$ 5.0). The images of Fluo-4 AM labelled mycelia were viewed using an S Plan Fluor ELWD microscope at $20 \times$ magnification with a 0.5 numerical aperture objective and digital sight camera on an Eclipse Ti inverted microscope system (Nikon, Tokyo, Japan) equipped with an FITC filter (420-490 nm bandpass excitation filter and $535 \mathrm{~nm}$ emission filter). The intensity of green fluorescence was quantified using the NIS-Elements F package software.

\section{Construction of plasmids and strains}

To construct the acy1 deletion mutant, the 799 bp upstream and $718 \mathrm{bp}$ downstream fragments of acy1 were generated from the genome of T. reesei QM6a using KOD-Plus-Neo (TOYOBO, Osaka, Japan). The primers used are listed in Additional File 14: Table S6. First, the upstream fragment was ligated into the $\mathrm{PacI}$ and $\mathrm{Xba \textrm {I }}$ linearized LML2.1 [45] using the pEASY $^{\circledR}$-Uni Seamless Cloning and Assembly Kit (TransGen Biotech) to form pFacy1. Subsequently, the downstream fragment was inserted into SwaI-linearised pFacyl to form the binary vector pDacy1 (Additional File 1: Figure S1) for the knockout of acy1 in QM6a using Agrobacteriummediated transformation [46]. The putative acy1 disruption mutants $(\triangle a c y 1)$ generated by double crossover were verified by diagnostic PCR using the primers acy1-CF and acy1-CR and acy1-OF and acy1-OR (Additional File 1: Figure $\mathrm{S} 1$ ).

The correct acy1 deletion strains should have a single copy of the 5- and 3-flanks of the acy1 gene as that in the wild-type strain QM6a (acy1-F and acy1-R; Additional File 1: Figure S1a). The integration of single-copy DNA fragments into transformed clones was verified using RT-qPCR (Additional File 1: Figure S1a-b) following previous studies $[47,48]$. Fungal genomic DNA was extracted using fungal DNA extraction kits (TianGen, Beijing, China). Genomic DNA was sonicated on ice in 30-s pulses using a Bioruptor (Diagenode s.a. BELGIUM) at low power to shear chromatin to an average length of 500-5000 bp. DNA was then used as a template for RTqPCR. The genome of QM6a with a single copy of the 5and 3-flanking acy 1 gene was used as a reference (acy1-F and acy1-R; Additional File 1: Figure S1a). The sar1 gene was used as a reference gene, using the primers sar1-3/ sar1-4. The primers used for the genes are listed in Additional File 14: Table S6.

The re-complementation cassettes of acyl were constructed by ligating the entire native acyl expression cassette, including the native promoter, acy1 coding sequence, and terminator, to the SwaI site of LML2.1. The complementation vector pRacy 1 and the re-complementation mutants of acyl (Racy1) were generated using Agrobacterium-mediated transformation (Additional File 1: Figure S1). The re-complementation mutants of plc-e (Rplc-e) were constructed similarly.

\section{Transcriptome analysis}

The transcriptomes of $T$. reesei QM6a cultured alone or with $10 \mathrm{mM} \mathrm{Mn}^{2+}$ or $1 \%$ DMF [20] were compared. Conidia $\left(2 \times 10^{6}\right)$ were cultivated at $28{ }^{\circ} \mathrm{C}(200 \mathrm{rpm})$ in $50 \mathrm{~mL}$ of MM (2\% glucose as the sole carbon source) for 36-48 h. The mycelia were inoculated in $100 \mathrm{~mL}$ of freshly prepared MM containing $1 \%$ Avicel as the sole carbon source, with either no further addition of components or with the addition of $10 \mathrm{mM} \mathrm{Mn}^{2+}$ or $1 \%$ DMF grown for $36 \mathrm{~h}$. Mycelia were then harvested from the cultures. All the mycelia of the WT (wild-type strain QM6a with no addition, prepared in duplicate), $\mathrm{Mn}$ (wild-type strain QM6a with $10 \mathrm{mM} \mathrm{Mn}^{2+}$ addition, prepared in duplicate), and DMF (wild-type strain QM6a with 1\% DMF addition, prepared in duplicate) were pooled, resulting in six samples. The samples were sent to a company (mega genomics, Beijing, China) for preparation and RNA sequencing using a HiSeq X Ten apparatus (Illumina, San Diego, CA, USA). Two biological replicates of each condition were submitted for RNA sequencing. Differential expression analysis was performed using DESeq [49]. Genes whose adjusted $P$ values were lower than 0.01 , and whose $\log 2$-fold change values 
were lower than -1 or higher than 1 were selected as differentially expressed genes (DEGs).

Processing of individual samples was successful without a significant difference between the replicates (Additional File 15: Table S7). Following sequence quality control, the sequence reads were mapped to a $T$. reesei reference genome (genome.jgi.doe.gov/Trire2/Trire2. home.html) with 93.87 to $94.80 \%$ coverage (Additional File 15: Table S7) for bioinformatics analysis. There was a high correlation (Pearson correlation, $\mathrm{r}^{2} \geq 0.898$ ) between the two biological replicates of each condition used in the transcriptional analysis (Additional File 16: Figure S9).

The raw whole transcriptome shotgun sequencing data and the related protocols are available at the NCBI SRA web site (https://www.ncbi.nlm.nih.gov/sra/PRJNA51036 6) under accession number PRJNA510366.

\section{Statistical analysis}

All experimental data shown in this paper were obtained from at least three independent samples with identical or similar results. The error bars indicate standard deviations (SDs) from the mean of triplicate determinations. Student's $t$-test was used to compare two samples. Duncan's multiple-range test was used for multiple comparisons. Within each set of experiments, $p<0.05$ was considered to indicate a significant difference.

\section{Supplementary Information}

The online version contains supplementary material available at https://doi. org/10.1186/s13068-021-01914-0.

\section{Additional file 1: Figure $\mathbf{S 1}$. Construction and verification of $\Delta a c y 1$} strains. a. Schematic representation of the acy 1 locus from the QM6a and $\triangle a c y 1$ strains. The region from +1 to +6649 bp relative to the translation start site of acy 1 (grey box) was replaced with the hygromycin cassette (black box). The binding sites of primers on the genome of QM6a and $\triangle a c y 1$ are indicated by red arrows. The binding sites of primers on the hygromycin cassette are indicated by blue arrows. The expected sizes of the PCR verification products in the $\triangle a c y 1$ strains are indicated as numbers. Primer pairs (acy1-T1/ acy1-T2 and acy1-T3/acy1-T4) shown in purple were used to identify the copy number of integrated genes. b. Schematic representation of the Pacy1-acy1-Tacy 1 cassette in Racy 1 strains. The acy 1 complementation cassette was constructed by ligating the whole gene sequence (including the $1500 \mathrm{bp}$ promoter, coding sequence, and $500 \mathrm{bp}$ terminator) into LML2.1. The primer pairs indicated were used in the verification of the expression cassette. c. PCR verification of $\triangle a c y 1$ strains. Lane M, DNA molecular mass maker Lane F, PCR amplification results using the acy1-CF/D70-4 pair. Lane R, PCR amplification results using the HG3.6/ acy1-CR pair. Lane O, PCR amplification results using the acy1-OF/acy1-OR pair. Lane N, PCR amplification results using acy1-OF/ acy1-OR pair with water as a negative control. $\triangle$ acy1-1, $\triangle$ acy $1-2$, and $\triangle$ acy $1-3$ represent three $\triangle a c y 1$ strains. QM6a as controls. d. PCR verification of Racy1 strains. Lane M, DNA molecular mass maker Lanes, PCR amplification results using the acy1-OF/acy1-OR pair with three Racy 1 strains and $\triangle a c y 1$ strains as templates. e. Verification of copy numbers for $\triangle \mathrm{acy} 1$ transformants by qPCR. The genome of QM6a was used as a reference with a single copy. f. Growth rates of wild-type QM6a, $\triangle a c y 1$, and Racy1 strains in MM plates.

Additional file 2: Figure S2. Cellulase activities of T. reesei complementary strains Racy1 and Rplc-e under different addition conditions. pNPCase activity/mg biomass of T. reesei QM6a, Racy1 and Rplc-e strains supplemented with $10 \mathrm{mM} \mathrm{Mn2+}$ or 1\% DMF. T. reesei QM6a was used as the control. Values are the mean \pm SD of the results from three independent experiments. Asterisks indicate significant differences from the control ( ${ }^{*} p$ $<0.05$, Student's t test).

Additional file 3: Figure S3. Effect of Mn2+/DMF/CAMP-induced cellulase overexpression. $a$ and b. pNPCase activity/mg biomass (a) and CMCase activity/mg biomass (b) of T. reesei QM6a and $\triangle$ acy 1 strains supplemented with $5 \mathrm{mM}$ dbcAMP, $10 \mathrm{mM} \mathrm{Mn2}+$ or (and) 1\% DMF. Values are the means $\pm S D$ of the results from three independent experiments. Asterisks indicate significant differences from the control $\left({ }^{*} p<0.05\right.$, Student's t test).

Additional file 4: Figure S4. Relative expression levels of cam (c), cna1 (d) and $\mathrm{crz} 1$ (e) in T. reesei QM6a and $\triangle \mathrm{acy} 1$ strains under different conditions. The QM6a and $\triangle \mathrm{acy} 1$ strains were cultured in MM with $2 \%$ glucose as the carbon source and then inoculated in fresh MM supplemented with 10 mM Mn2+, 1\% DMF, 0.02 mM Forskolin, or 5 mM dbcAMP, with 1\% Avicel as the carbon source. Cultures that were not supplemented with $\mathrm{Mn} 2+$, DMF, Forskolin, or dbcAMP were used as controls. QM6a cells cultured without the addition of Mn2+, DMF, Forskolin, or dbcAMP were used as the reference sample. Values are expressed as the mean \pm SD of the results from three independent experiments. Asterisks indicate significant differences from the control $\left({ }^{*} \mathrm{p}<0.05\right.$, Student's $t$ test).

Additional file 5: Figure S5. Effect of CAMP/LaCl3-induced cellulase overexpression. a and b. pNPCase activity/mg biomass (a) and CMCase activity/mg biomass (b) of T. reesei QM6a strains supplemented with 5 $\mathrm{mM}$ dbcAMP and $5 \mathrm{mM} \mathrm{LaCl} 3$. Values are the means $\pm \mathrm{SD}$ of the results from three independent experiments. Asterisks indicate significant differences from the control ( ${ }^{*} p<0.05$, Student's $t$ test).

Additional file 6: Figure S6. Volcano plot analysis of up- and downregulated genes of strains treated with or without $10 \mathrm{mM} \mathrm{Mn2}+$ treatment. Volcano plot for differences in gene expression with no addition or $10 \mathrm{mM}$ $\mathrm{Mn} 2+$ addition. Red dots indicate significantly upregulated genes, green dots indicate significantly downregulated genes, and grey dots indicate non-significantly different gene expression. The $x$-axis represents the logarithm of the differential multiple of a gene expression in two samples. The $y$-axis represents the negative log of a statistically significant change in gene expression. Control: parental strain QM6a without $10 \mathrm{mM} \mathrm{Mn2+}$

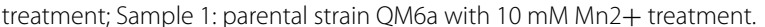

Additional file 7: Table S1. Genes that are significantly up- or down-

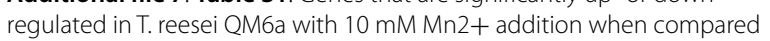
with no addition.

Additional file 8: Table S2. Differential transcription of genes in response to $\mathrm{Mn} 2+$ and DMF as measured by RNA-sequencing.

Additional file 9: Table S3. The log2 fold changes of the major cellulose degradation-related genes under Mn2+/DMF addition conditions.

Additional file 10: Table S4. Whole transcriptome shotgun sequencing data and RT-qPCR verification of the plc-e gene under $\mathrm{Mn} 2+$ addition conditions.

Additional file 11: Figure S7. The growth rate related cellulase activity and transcription levels of $\mathrm{cbh} 1$ and egl1 after $\mathrm{Mn} 2+$ stimulation in wildtype QM6a and $\triangle$ plc-e mutant.

Additional file 12: Figure S8. Relative expression levels of cam (c), cna1 (d), and crz1 (e) in T. reesei QM6a and $\triangle$ plc-e strains. The QM6a and $\Delta$ plc-e strains were cultured in MM with $2 \%$ glucose as the carbon source and then inoculated in fresh MM supplemented with $10 \mathrm{mM} \mathrm{Mn2+,1 \%} \mathrm{DMF,}$ $0.02 \mathrm{mM}$ Forskolin, or $5 \mathrm{mM}$ dbcAMP, with 1\% Avicel as the carbon source. Cultures with no addition were used as controls. QM6a cells cultured with no addition were used as the reference sample. Values are expressed as the mean $\pm S D$ of the results from three independent experiments. Asterisks indicate significant differences from the control ${ }^{*} p<0.05$, Student's t test).

Additional file 13: Table S5. The log2 fold changes of the putative GPCRs genes under Mn2+/DMF addition conditions. 


\section{Additional file 14: Table S6. Primers used in this study.}

Additional file 15: Table S7. Sequencing statistics for whole transcriptome shotgun sequencing results from this study.

Additional file 16: Figure S9. Biological replicates used for wholetranscriptome shotgun sequencing analysis. Graphs representing the Pearson correlation between biological replicates of each sample. A high Pearson correlation was obtained, demonstrating the reliability of whole transcriptome shotgun sequencing analysis ( $r 2 \geq 0.898)$. The $x$-axis and $y$-axis correspond to the gene expression in different treatments (e.g., experiment or control) after conversion by $\log 2(\mathrm{FPKM}+1)$.

\section{Acknowledgements}

Not applicable

\section{Authors' contributions}

WW initiated, designed, and coordinated the study and reviewed the manuscript. YC planned and carried out experiments and measurements, and interpreted the experimental data. XF and LW performed some experiments. DW, $X Z, X X$, and $Y S$ provided useful advice. All authors have read and approved the final manuscript.

\section{Funding}

The project was funded by the National Natural Science Foundation of China (32000050) and the China Postdoctoral Science Foundation funded project (No. 2019M661402).

\section{Availability of data and materials}

All data generated or analysed during this study are included in this published article [and its supplementary information files]

\section{Ethics approval and consent to participate}

Not applicable.

\section{Consent for publication}

Not applicable.

\section{Competing interests}

The authors declare no conflict of interest.

\section{Author details}

${ }^{1}$ State Key Lab of Bioreactor Engineering, New World Institute of Biotechnology, East China University of Science and Technology, 130 Meilong Road P.O.B. 311, Shanghai 200237, China. ${ }^{2}$ State Key Laboratory of Microbial Metabolism, Joint International Research Laboratory of Metabolic and Developmental Sciences, School of Life Sciences and Biotechnology, Shanghai Jiao Tong University, Shanghai 200240, China. ${ }^{3}$ Zaozhuang Jie Nuo Enzyme Co. Ltd., Shandong, China.

Received: 29 December 2020 Accepted: 21 February 2021 Published online: 08 March 2021

\section{References}

1. Antonieto ACC, Nogueira KMV, De Paula RG, Nora LC, Cassiano MHA, Guazzaroni ME, Almeida F, Da Silva TA, Ries LNA, De Assis LJ, Goldman GH, Silva RN, Silva-Rocha R. A novel Cys2His2 zinc finger homolog of AZF1 modulates holocellulase expression in Trichoderma reesei. mSystems. 2019;4:e00161-e219.

2. Golecha R, Gan JB. Cellulosic biorefinery portfolio and diversification: Strategies to mitigate cellulosic biorefinery risks in US Corn Belt. Energy Strateg Rev. 2016;13-14:147-53.

3. Novy V, Nielsen F, Seiboth B, Nidetzky B. The influence of feedstock characteristics on enzyme production in Trichoderma reesei: a review on productivity, gene regulation and secretion profiles. Biotechnol Biofuels. 2019;12:238.
4. Glass NL, Schmoll M, Cate JHD, Coradetti S. Plant cell wall deconstruction by ascomycete fungi. Annu Rev Microbiol. 2013;67:477-98.

5. Liu G, Qu Y. Engineering of filamentous fungi for efficient conversion of lignocellulose: tools, recent advances and prospects. Biotechnol Adv. 2018:37:519-29.

6. Znameroski EA, Glass NL. Using a model filamentous fungus to unravel mechanisms of lignocellulose deconstruction. Biotechnol Biofuels. 2013;6:6.

7. Bischof RH, Ramoni J, Seiboth B. Cellulases and beyond: the first 70 years of the enzyme producer Trichoderma reesei. Microb Cell Fact. 2016;15:106.

8. Gupta VK, Steindorff AS, de Paula RG, Silva-Rocha R, Mach-Aigner AR, Mach RL, Silva RN. The Post-genomic Era of Trichoderma reesei: What's Next? Trends Biotechnol. 2016;34:970-82.

9. Meng Q, Zhang F, Liu C, Zhao X, Bai F. Identification of a novel repressor encoded by the putative gene ctf1 for cellulase biosynthesis in Trichoderma reesei through artificial zinc finger engineering. Biotechnol Bioeng. 2020;117:1747-60.

10. de Paula RG, Antonieto ACC, Ribeiro LFC, Srivastava N, O'Donovan A, Mishra PK, Gupta VK, Silva RN. Engineered microbial host selection for value-added bioproducts from lignocellulose. Biotechnol Adv. 2019;37:107347.

11. Schmoll M. The information highways of a biotechnological workhorsesignal transduction in Hypocrea jecorina. BMC Genomics. 2008;9:430.

12. Chen L, Zou G, Wang J, Wang J, Liu R, Jiang Y, Zhao G, Zhou Z. Characterization of the $\mathrm{Ca}^{2+}$-responsive signaling pathway in regulating the expression and secretion of cellulases in Trichoderma reesei Rut-C30. Mol Microbiol. 2016;100:560-75.

13. Schmoll M. Light, stress, sex and carbon-The photoreceptor ENVOY as a central checkpoint in the physiology of Trichoderma reesei. Fungal Biol. 2018;122:479-86

14. Schuster A, Tisch D, Seidl-Seiboth V, Kubicek CP, Schmoll M. Roles of protein kinase $A$ and adenylate cyclase in light-modulated cellulase regulation in Trichoderma reesei. Appl Environ Microbiol. 2012;78:2168-78.

15. Wang M, Zhang M, Li L, Dong Y, Jiang Y, Liu K, Zhang R, Jiang B, Niu K, Fang $X$. Role of Trichoderma reesei mitogen-activated protein kinases (MAPKs) in cellulase formation. Biotechnol Biofuels. 2017;10:99.

16. Hernandez-Ortiz P, Espeso EA. Phospho-regulation and nucleocytoplasmic trafficking of CrzA in response to calcium and alkaline-pH stress in Aspergillus nidulans. Mol Microbiol. 2013;89:532-51.

17. Hernandez-Ortiz P, Espeso EA. Spatiotemporal dynamics of the calcineurin target CrzA. Cell Signal. 2017;29:168-80.

18. Martins-Santana L, Paula RG, Silva AG, Lopes DCB, Silva RDN, SilvaRocha R. CRZ1 regulator and calcium cooperatively modulate holocellulases gene expression in Trichoderma reesei QM6a. Genet Mol Biol. 2020;43:e20190244.

19. Chen Y, Shen Y, Wang W, Wei D. $\mathrm{Mn}^{2+}$ modulates the expression of cellulase genes in Trichoderma reesei Rut-C30 via calcium signaling. Biotechnol Biofuels. 2018;11:54

20. Chen Y, Wu C, Shen Y, Ma Y, Wei D, Wang W. N, N-dimethylformamide induces cellulase production in the filamentous fungus Trichoderma reesei. Biotechnol Biofuels. 2019;12:36.

21. Šesták S, Farkaš V. Metabolic regulation of endoglucanase synthesis in Trichoderma reesei: participation of cyclic AMP and glucose-6-phosphate. Can J Microbiol. 1993;39:342-7.

22. Schmoll M, Schuster A, Silva Rdo N, Kubicek CP. The G-Alpha Protein GNA3 of Hypocrea jecorina (Anamorph Trichoderma reesei) regulates cellulase gene expression in the presence of light. Eukaryot Cell. 2009;8:410-20

23. Tisch D, Kubicek CP, Schmoll M. New insights into the mechanism of light modulated signaling by heterotrimeric G-proteins: ENVOY acts on gna1 and gna3 and adjusts CAMP levels in Trichoderma reesei (Hypocrea jecorina). Fungal Genet Biol. 2011;48:631-40.

24. Nogueira KM, Costa Mdo N, de Paula RG, Mendonca-Natividade FC, RicciAzevedo R, Silva RN. Evidence of CAMP involvement in cellobiohydrolase expression and secretion by Trichoderma reesei in presence of the inducer sophorose. BMC Microbiol. 2015;15:195.

25. Rato C, Monteiro D, Hepler PK, Malho R. Calmodulin activity and CAMP signalling modulate growth and apical secretion in pollen tubes. Plant J. 2004;38:887-97. 
26. Yang J, Gong Y, Liu Q, Cai J, Zhang B, Zhang Z. Thioredoxin silencinginduced cardiac supercontraction occurs through endoplasmic reticulum stress and calcium overload in chicken. Metallomics. 2018;10:1667-77.

27. Thewes S. Calcineurin-Crz1 signaling in lower eukaryotes. Eukaryot Cell. 2014;13:694-705.

28. Wang D, Qu Y, Gao P. Regulation of cellulase synthesis in mycelial fungi: participation of ATP and cyclic AMP. Biotechnol Lett. 1995;17:593-8.

29. Gruber S, Omann M, Zeilinger S. Comparative analysis of the repertoire of $\mathrm{G}$ protein-coupled receptors of three species of the fungal genus Trichoderma. Bmc Microbiol. 2013;13:108.

30. Logan A, Collier A, Katherine AB. Heterotrimeric G-protein signaling is required for cellulosedegradation in Neurospora crassa. mBio. 2020;6:e02419-e2420.

31. Li L, Wright SJ, Krystofova S, Park G, Borkovich KA. Heterotrimeric G protein signaling in filamentous fungi. Annu Rev Microbiol. 2007;61:423-52.

32. Kraakman L, Lemaire K, Ma PS, Teunissen AWRH, Donaton MCV, Van Dijck P, Winderickx J, de Winde JH, Thevelein JM. A Saccharomyces cerevisiae G-protein coupled receptor, Gpr1, is specifically required for glucose activation of the CAMP pathway during the transition to growth on glucose. Mol Microbiol. 1999:32:1002-12.

33. Xue C, Bahn YS, Cox GM, Heitman J. G protein-coupled receptor Gpr4 senses amino acids and activates the CAMP-PKA pathway in Cryptococcus neoformans. Mol Biol Cell. 2006;17:667-79.

34. Lange M, Peiter E. Calcium transport proteins in fungi: The phylogenetic diversity of their relevance for growth, virulence, and stress resistance. Front Microbiol. 2019;10:3100.

35. Beraldo FH, Almeida FM, da Silva AM, Garcia CR. Cyclic AMP and calcium interplay as second messengers in melatonin-dependent regulation of Plasmodium falciparum cell cycle. J Cell Biol. 2005;170:551-7.

36. Gao T, Shi L, Zhang T, Ren A, Jiang A, Yu H, Zhao M. Cross talk between calcium and reactive oxygen species regulates hyphal branching and ganoderic acid biosynthesis in Ganoderma lucidum under copper stress. Appl Environ Microbiol. 2018;84:e00438-e518.

37. Wang $H$, Liang $Y$, Zhang B, Zheng W, Xing L, Li M. Alkaline stress triggers an immediate calcium fluctuation in Candida albicans mediated by Rim101p and Crz1p transcription factors. FEMS Yeast Res. 2011;11:430-9.

38. Benčina M, Legisa M, Read ND. Cross-talk between CAMP and calcium signalling in Aspergillus niger. Mol Microbiol. 2005;56:268-81.
39. Hanson CJ, Bootman MD, Roderick HL. Cell signalling: IP3 receptors channel calcium into cell death. Curr Biol. 2004;14:R933-5.

40. Schmidt M, Evellin S, Weernink PA, von Dorp F, Rehmann H, Lomasney JW Jakobs KH. A new phospholipase-C-calcium signalling pathway mediated by cyclic AMP and a Rap GTPase. Nat Cell Biol. 2001;3:1020-4.

41. Schumacher J, Viaud M, Simon A, Tudzynski B. The Galpha subunit BCG1, the phospholipase C (BCPLC1) and the calcineurin phosphatase co-ordinately regulate gene expression in the grey mould fungus Botrytis cinerea. Mol Microbiol. 2008:67:1027-50.

42. Michielse CB, Hooykaas PJJ, Van Den Hondel CAMJJ, Ram AFJ. Agrobacterium-mediated transformation of the filamentous fungus Aspergillus awamori. Nat Protocols. 2008;3:1671-8.

43. Steiger MG, Mach RL, Mach-Aigner AR. An accurate normalization strategy for RT-qPCR in Hypocrea jecorina (Trichoderma reesei). J Biotechnol. 2010;145:30-7.

44. Yang K, Qin Q, Liu Y, Zhang L, Liang L, Lan H, Chen C, You Y, Zhang F, Wang S. Adenylate cyclase AcyA regulates development, aflatoxin biosynthesis and fungal virulence in Aspergillus flavus. Front Cell Infect Microbiol. 2016;6:190

45. Zhang L, Zhao X, Zhang G, Zhang J, Wang X, Zhang S, Wang W, Wei D. A light-switchable bidirectional expression system in filamentous fungus Trichoderma reesei. J Biotechnol. 2016;240:85-93.

46. Zhang G, Liu P, Wei W, Wang X, Wei D, Wang W. Light-inducible genetic engineering and control of non-homologous end-joining in industrial eukaryotic microorganisms: LML 3.0 and OFN 1.0. Sci Rep. 2016;6:20761.

47. Li C, Lin F, Zhou L, Qin L, Li B, Zhou Z, Jin M, Chen Z. Cellulase hyperproduction by Trichoderma reesei mutant SEU-7 on lactose. Biotechnol Biofuels. 2017;10(1):228.

48. Tisch D, Kubicek CP, Schmoll M. The phosducin-like protein PhLP1 impacts regulation of glycoside hydrolases and light response in Trichoderma reesei. BMC Genomics. 2011;12(1):613.

49. Anders S, Huber W. Differential expression analysis for sequence count data. Genome Biol. 2010;11(10):R106.

\section{Publisher's Note}

Springer Nature remains neutral with regard to jurisdictional claims in published maps and institutional affiliations.
Ready to submit your research? Choose BMC and benefit from:

- fast, convenient online submission

- thorough peer review by experienced researchers in your field

- rapid publication on acceptance

- support for research data, including large and complex data types

- gold Open Access which fosters wider collaboration and increased citations

- maximum visibility for your research: over $100 \mathrm{M}$ website views per year

At BMC, research is always in progress.

Learn more biomedcentral.com/submissions 